\title{
HSV-2: in pursuit of a vaccine
}

\author{
Christine Johnston,1,2 David M. Koelle,1,2,3,4,5 and Anna Wald1,2,3,6 \\ 1Department of Medicine, University of Washington, Seattle, Washington, USA. ${ }^{2}$ Vaccine and Infectious Disease Division, Fred Hutchinson Cancer Research Center, \\ Seattle, Washington, USA. ${ }^{3}$ Department of Laboratory Medicine and ${ }^{4}$ Department of Global Health, University of Washington, Seattle, Washington, USA. \\ ${ }^{5}$ Benaroya Research Institute, Seattle, Washington, USA. ${ }^{6}$ Department of Epidemiology, University of Washington, Seattle, Washington, USA.
}

\begin{abstract}
Herpes simplex virus type 2 (HSV-2) is one of the most prevalent sexually transmitted infections worldwide. In addition to recurrent genital ulcers, HSV-2 causes neonatal herpes, and it is associated with a 3-fold increased risk for HIV acquisition. Although many HSV-2 vaccines have been studied in animal models, few have reached clinical trials, and those that have been tested in humans were not consistently effective. Here, we review HSV-2 pathogenesis, with a focus on novel understanding of mucosal immunobiology of HSV-2, and vaccine efforts to date, in an attempt to stimulate thinking about future directions for development of effective prophylactic and therapeutic HSV-2 vaccines.
\end{abstract}

\section{Introduction}

Herpes simplex virus type 2 (HSV-2) is a sexually transmitted pathogen that infects more than 500 million people worldwide and causes an estimated 23 million new infections each year (1). HSV-2 seroprevalence ranges from 16\% among 14-49 year olds in the United States (2) to greater than $80 \%$ in some areas of subSaharan Africa (3); seroprevalence in women is up to twice as high as men, and increases with age $(2,4)$. Although HSV-2 is the leading cause of genital ulcer disease worldwide $(5,6)$, most people are not aware of the infection (7), and may transmit the virus during periods of subclinical shedding $(8,9)$. In contrast to other sexually transmitted infections (STIs) that may be concentrated among "core groups," such as gonorrhea (10), HSV-2 is widespread even among people with low or moderate levels of sexual activity. For instance, $18.8 \%$ of American women with 2-4 lifetime sexual partners are HSV-2 seropositive (2).

Although incident genital herpes is increasingly caused by HSV type 1 (HSV-1; ref. 11), and HSV-1 may also cause significant eye and brain disease, almost all HSV vaccine candidates reaching clinical trials have targeted HSV-2. As HSV-1 and HSV-2 have similar pathogenesis and host interactions, many of the concepts for development of an effective vaccine are likely relevant to both viruses. In addition, infection with HSV-2 provides partial protection against HSV-1 (12), although the reverse does not appear to be true (13), and thus there is potential for generation of cross-reactive immunity (14). The possibility that an HSV-2 vaccine may provide protection against HSV-1 increases its potential value and may shift the optimal time for immunization to early childhood, instead of the more problematic adolescent vaccination series (15).

Transmission of HSV from mother to infant during birth is the most serious complication of genital herpes, and women who acquire HSV during pregnancy are at the highest risk of transmitting the infection (16). Neonatal herpes often results in long-term neurologic sequelae or mortality (17). The estimated incidence of

Conflict of interest: Christine Johnston is a research investigator and Anna Wald is a consultant for AiCuris $\mathrm{GmbH}$, which is developing treatments for HSV and cytomegalovirus infections. David M. Koelle is listed as a coinventor on several patents describing antigens and epitopes to which T cell responses to HSV-2 are directed; has been a consultant to GlaxoSmithKline concerning papillomavirus vaccines and to Sanofi-Pasteur, Agenus, and Immune Design Corporation concerning HSV-2 vaccines; and is or has recently been contracted by Coridon Pty Ltd., Vical Inc., and PATH for preclinical evaluation of candidate HSV-2 vaccines.

Citation for this article: J Clin Invest. 2011;121(12):4600-4609. doi:10.1172/JCI57148. neonatal herpes varies widely, from 4 to 31 in 100,000 live births $(12,18)$. Although neonatal herpes is too rare to be used as an endpoint in a clinical vaccine trial, prevention of HSV acquisition during pregnancy is an important goal of developing an effective HSV vaccine.

The risk of HIV-1 acquisition is 3-fold higher among HSV-2seropositive persons (19); in populations with $80 \%$ seroprevalence, nearly $50 \%$ of HIV infections are attributable to prevalent HSV-2 (20). The mechanism of increased risk of HIV acquisition includes influx of HIV target cells (21) in response to HSV-2 replication in the genital mucosa. Thus, decreasing either HSV-2 susceptibility or reactivation through prophylactic vaccination could lead to a marked decrease in HIV incidence in sub-Saharan Africa (22).

Prevention strategies for sexual transmission of HSV-2 include condom use (23), disclosure of serostatus (24), and suppressive antiviral therapy (23). However, these methods are imperfect, as each reduces transmission by only approximately $50 \%(25,26)$. Moreover, antiviral therapy does not abrogate the increased risk of HIV acquisition $(27,28)$ or transmission (29) in HSV-2-seropositive persons. The currently available strategies are useful for individual patients, but they are unlikely to be of public health benefit. A prophylactic vaccine would be valuable from both the patient and public health standpoint, if it were able to meet or exceed the efficacy of currently available preventive therapies.

\section{New insights into HSV pathogenesis: frequent and dynamic reactivation}

HSV infects epithelial cells at skin and mucosal surfaces during primary infection, then travels via retrograde transport along nerve axons to the dorsal root ganglia (DRG), where latency is established (30). While epithelial cells are destroyed during lytic HSV replication, neuronal cells are not destroyed and provide a reservoir for latent virus. During reactivation, the virus travels from the DRG back to the skin and causes detection of virus from epithelial surfaces (known as viral shedding). Viral reactivation may be asymptomatic or may be associated with prodrome (tingling or burning), nonspecific symptoms or lesions, or a classic genital ulcer.

Studies that measure the frequency of viral shedding and the quantity of virus detected from the genital tract have provided insight into the natural history and pathogenesis of HSV-2 infection. HSV was previously thought to be in the latent state most of the time during chronic infection, with rare clinically evident 
reactivation episodes, conceptually similar to varicella zoster virus (VZV). However, shedding studies using anogenital swabs collected by HSV-2-seropositive persons once or multiple times daily for viral culture or for quantitative real-time PCR have revealed that HSV and the host are in constant conflict, with frequent HSV reactivation and rapid clearance (31). This implies host responses that likely involve cell-intrinsic and -extrinsic mechanisms of innate as well as acquired immunity. In studies in which HSV-2-infected persons collect daily genital swabs, HSV is detected on a median of $12 \%-28 \%$ of days (32) and is found on $10 \%$ of days even among persons with asymptomatic HSV-2 infection (33). Many of these shedding episodes occur in the absence of lesions or symptoms (known as subclinical shedding; ref. 34). Mathematical models suggest that multiple, short, overlapping shedding episodes best simulate the observed shedding patterns (35) and that a nearly constant low quantity of HSV is likely to be released from sensory DRG into the genital tract (36). Recent studies using intensive sampling (every 6 hours) of the genital and oral mucosa have produced results consistent with these models, demonstrating that most HSV detection episodes are short (median 13 hours), subclinical, and rapidly cleared (31). In addition, studies using detailed genital mapping to isolate shedding episodes have demonstrated that simultaneous, bilateral widespread genital shedding is detected frequently (37). HSV lesions are associated with persistent infiltrate of $\mathrm{CD}^{+}$and $\mathrm{CD}^{+} \mathrm{T}$ cells in the mucosa $(21,38)$ and at nerve endings $(38)$ that may contribute to a chronic inflammatory state in genital skin and mucosa. In support of this hypothesis, histopathologic studies of foreskin in HIV-seronegative men after adult circumcision have shown a higher concentration of $\mathrm{CD}^{+}$and $\mathrm{CD}^{+} \mathrm{T}$ cells in HSV-2-seropositive compared with HSV-2-seronegative men (39). Thus, even persons with established infection and a functional immune system can experience both subclinical genital HSV shedding and lesional recurrences, which suggests that the virus can evade even mature host immune responses. These findings indicate that chronic HSV infection involves a dynamic equilibrium between ganglionic and mucosal compartments.

\section{HSV-2 transmission dynamics}

HSV-2 infection rates in heavily exposed populations, such as commercial sex workers, are nearly $100 \%$, suggestive of near-universal susceptibility (40). Studies in HSV-2-discordant couples have shown that most HSV-2 transmissions occur during periods of subclinical shedding in the source partner (8). The relationship between the inoculum dose, the presence of local abrasions or other epithelial variables, and the likelihood of successful transmission has not been established in humans. An increase in the inoculum dose required to produce disease or establish ganglionic latency might result from a vaccine, as has been shown with a live attenuated candidate vaccine in guinea pigs (41), providing partial protection from infection or disease.

HSV-2 is transmitted between sexual partners fairly quickly in a new sexual relationship. In a cohort of 199 patients with laboratory-documented primary HSV-2 infection and a clearly defined transmitting partner, the median number of sexual acts between the couple at the time of HSV-2 acquisition was 40 (24). Obversely, our group has identified some HSV-2-seronegative persons in long-term HSV-2-discordant sexual relationships who have $\mathrm{T}$ cell responses to HSV-2 (42), which suggests that not all exposures result in infection. Preliminary data suggest that these $T$ cell responses may be weighted toward certain HSV-2 proteins (42). If confirmed and extended using the whole HSV-2 proteome, this finding could indicate preferred compositions for future subunit vaccines.

Experts have long considered infection by multiple HSV-2 strains in a given individual a rare phenomenon $(43,44)$, raising the potential for inducing sterilizing immunity. However, recent studies using more sensitive PCR techniques and newly identified variable regions in HSV-2 have found multiple-strain genital infection in $15 \%$ of healthy adults infected with genital HSV-1 and HSV-2 (45, 46). In a small cohort of HIV/HSV-2 coinfected persons, all 11 harbored more than one HSV-2 strain; however, the relative contributions of high sexual exposure versus immunosuppression to this observation has not been defined. Sterilizing immunity with other human herpesvirus infections is variable: wild-type infection with VZV protects against reinfection, whereas multiple strains of CMV are detected in more than $90 \%$ of CMV-infected women (47). A more detailed analysis of the prevalence of multistrain HSV-2 infection is now possible because of increased knowledge of viral SNPs $(48,49)$ and can be used to establish how well naturally occurring HSV-2 infection protects against infection with a second strain in humans. These data will discern whether immunity better than, or perhaps fundamentally different from, that provoked by wild-type infection will be a necessary component of a successful vaccine.

\section{The immune response to HSV-2}

HSV-2 induces an immune response that eventually contains the virus, as suggested by the temporal correlation of the infiltration of antigen-specific $\mathrm{CD}^{+}$and $\mathrm{CD}^{+} \mathrm{T}$ cells at the site of a lesion and clearance of virus (50). The importance of the host immune response is demonstrated by the severe, prolonged ulcerations that can occur in patients with AIDS (51) or after solid organ (52) or stem cell transplantation (53). The host and viral determinants of the heterogeneous clinical and virological manifestations of genital HSV-2 are poorly understood. In our opinion, identification of those components of the host immune system that result in containment of viral reactivation from neurons, and viral clearance from the mucosa, will be essential for development of a successful HSV-2 vaccine. This is most likely to be gained by detailed immunologic and genetic studies of persons with well-defined HSV-2 severity.

HSV stimulates the innate immune system to produce IFN- $\alpha$, through interactions with plasmacytoid DCs (pDCs; ref. 54) and other cells, via TLRs, including TLR9 (55), TLR2 (56), and TLR3 (57). Cytoplasmic DNA sensors, such as stimulator of IFN genes (STING), mediate production of IFN in response to HSV infection, as demonstrated in cell culture and in knockout mouse models (58). Interestingly, most host mutations associated with fatal HSV in childhood occur at loci classically associated with innate immunity, such as TLR3 (57) and UNC93B1 (59), although some mutations associated with severe HSV are in genes involved in both innate and acquired immune responses (e.g., STAT1), reflecting a complex codependence and interaction between these pathways (60). Although innate immune system agonists can lead to profound, local HSV resistance $(61,62)$, these interventions are outside the realm of classic vaccinology. Single nucleotide polymorphisms in TLR2 are associated with more frequent HSV shedding and genital lesions (63), which suggests that there may be a host genetic contribution to the wide heterogeneity of clinical HSV presentation. Curiously, IFN- $\alpha$ and the characteristic IFN type I gene signature are not present in biopsies of genital HSV-2 lesions (64), which indicates that despite HSV's powerful ability to trigger IFN- $\alpha$ in pDCs, there may be a defect in local type I 
IFN responses in situ. HSV-1 has also evolved mechanisms to downregulate IFN expression, for example, via IRF3 degradation mediated by immediate early infected cell protein 0 (ICP0), which prevents accumulation of IFN- $\beta$ (65). In addition, expression of ICP0 alone can prevent TLR2-dependent NF- $\kappa \mathrm{B}$ activation in cell culture, which suggests that the virus downregulates the immune response at several points in the inflammatory pathway (66).

$\mathrm{CD}^{+} \mathrm{T}$ cells are an important source of IFN- $\gamma$, have cytotoxic effector activity for HSV-infected cells, and localize to HSV-2 genital lesions (50). $\mathrm{CD}^{+} \mathrm{T}$ cell depletion is statistically associated with increased HSV-2 shedding in HIV-1 infection (67), albeit in the context of a multifaceted immune deficiency, including a profound reduction in circulating $\mathrm{pDCs}(68)$. In mice, $\mathrm{CD}^{+} \mathrm{T}$ cells play key protective roles after whole virus vaccination, as shown by depletion studies $(69,70)$. The presence of $\mathrm{CD}^{+} \mathrm{T}$ cells is associated with HSV clearance from the peripheral nervous system (71), and ganglionic HSV-specific T cells appear to be important in maintaining HSV-1 latency in the mouse model of infection (72). HSVspecific $\mathrm{CD}^{+} \mathrm{T}$ cells are chronically localized to HSV-infected DRG in humans and appear to be activated (73). Mathematical models predict that the duration and severity of HSV shedding episodes is strongly associated with a low density of $\mathrm{CD}^{+} \mathrm{T}$ cells in the genital mucosa (74). In studies using a subset of the predicted HSV proteome, HSV-2-seropositive persons generate a broad $\mathrm{CD}^{+} \mathrm{T}$ cell response, reacting to a median of 11 epitopes (75). These cells typically target immediate-early or early HSV genes and produce IFN- $\gamma$, but may be capable of proliferation, IL- 2 and TNF- $\alpha$ production, and cytolytic responses (e.g., increased expression of CD107a). No acquired cellular immunity correlates of control of HSV reactivation or shedding have been elucidated in humans.

Neutralizing antibodies to viral envelope glycoproteins, which are required for viral entry into cells, develop in response to HSV infection (76) and may provide some type-common protection against HSV acquisition (77) or reduce the severity of HSV infection $(78,79)$. As a result, glycoprotein $\mathrm{B}(\mathrm{gB})$ and $\mathrm{gD}$ subunit vaccines have been pursued in human clinical trials. Physiologically relevant host receptors have been defined (80), and crystallographic structures of HSV proteins with their ligands and dynamic structural changes during viral entry are newly available (81-83). These data may inform the design of a newer generation of glycoprotein-based vaccines designed to elicit optimal neutralizing antibodies, inspired by the success of HPV vaccines, which appear to work at least in part by eliciting higher titers of neutralizing antibodies than those induced by natural infection.

\section{Immune evasion}

Alphaherpesviruses, such as HSV-2, have coevolved with primate hosts for millions of years and have developed many strategies to evade the host immune response. The latency associated transcript blocks apoptosis and may allow for survival of neurons during latent infection (84), whereas other viral genes block apoptosis induced by cytolytic immune effector cells (85). Activated HSVspecific $\mathrm{CD}^{+} \mathrm{T}$ cells are found surrounding trigeminal DRG in HSV-1-infected persons, but there is no evidence that these cells kill the neurons, despite the expression of cytolytic proteins such as granzyme B (73). Several HSV proteins, such as the ubiquitin ligase ICP0, interact with the IFN pathway. Contact of T cells with HSV-infected cells inhibits and alters $\mathrm{T}$ cell signaling via intracellular phosphorylation cascades (86), and ICP47 blocks $\mathrm{CD}^{+} \mathrm{T}$ cell responses by interactions with the transporter associ- ated with antigen processing (TAP), which moves peptides to MHC class I (87). With the knowledge of specific HSV immune evasion mechanisms, it is possible to create replication-competent or -incompetent virus-based vaccines modified to disable inhibitors of innate and acquired immunity. Examples include deletion of UL41 (which encodes a protein with complex properties, including DC downregulation; ref. 88) from candidate vaccine strains (89) and deletion of multiple immune evasion genes from Immunove $\mathrm{X}^{\mathrm{HSV}-2}$, a live attenuated strain currently in phase I clinical trials (90).

Thus, although the components of protective immunity remain unknown, the tools to perform studies to correlate immunity with phenotype are now largely in place: immunocompetent subjects can be phenotyped for shedding frequency, the viral proteome is manageably sized for comprehensive immune studies, and specimens can include infected tissues as well as blood.

\section{Animal models of HSV vaccination}

The mouse and guinea pig models of HSV-2 infection have provided important insight into the immunobiology of genital herpes. The mouse model is limited because HSV does not spontaneously reactivate from mice DRG and therefore does not simulate infection in the human host. Some viral immune evasion mechanisms are also less active in mice. Although pathogenesis insights into tissue-resident HSV-specific T cells made in mice appear applicable to human infection $(91,92)$, most vaccine studies in mice use lethality as an endpoint and, due to space constraints, will not be reviewed here. The guinea pig does reactivate HSV spontaneously for a limited period of time after vaginal infection (93), but few reagents are available to parse out the components of an effective immune response in this model. As an alternative, the cotton rat model, in which HSV reactivation does occur, should be further exploited (94).

Many prophylactic vaccines have been tested in the guinea pig model, and most have been successful in preventing clinically apparent infection (Supplemental Table 1; supplemental material available online with this article; doi:10.1172/JCI57148DS1). In addition, several therapeutic vaccines prevent recurrences in this model. Approaches have included recombinant glycoprotein subunit vaccines, DNA-based vaccines using plasmids encoding glycoproteins, live virus vector vaccines with glycoprotein inserts, live-attenuated HSV-2, and replication-incompetent virus. These vaccines resulted in decreased severity of primary disease, rate of recurrent infection, and quantity of virus shed during primary infection and recurrent activation.

Studies in the guinea pig have shown the quantity of HSV that establishes latency in the DRG correlates with frequency of clinical recurrence (95), which suggests that partial protection could be a valuable endpoint goal in vaccine design. Several candidate vaccines appear to reduce the quantity of HSV in the guinea pig DRG. However, once DRG are infected, shedding still occurs at a rate similar to that of nonimmunized animals $(96,97)$. These data suggest that once neuronal infection in the DRG is established, the pathobiology of frequent reactivation may not be affected by a therapeutic vaccine, although clinical recurrences and quantity of virus shed may be diminished. In parallel, long-term studies of HSV-2-infected persons show that most, if not all, reactivate HSV-2, albeit with variable frequency (98).

In the HIV vaccine field, a new pipeline for preclinical testing of $\mathrm{T}$ cell-based vaccines in nonhuman primates has been proposed (99), which requires efficacy for a clinically relevant, predefined virologic endpoint, followed by examination of immunogenicity 


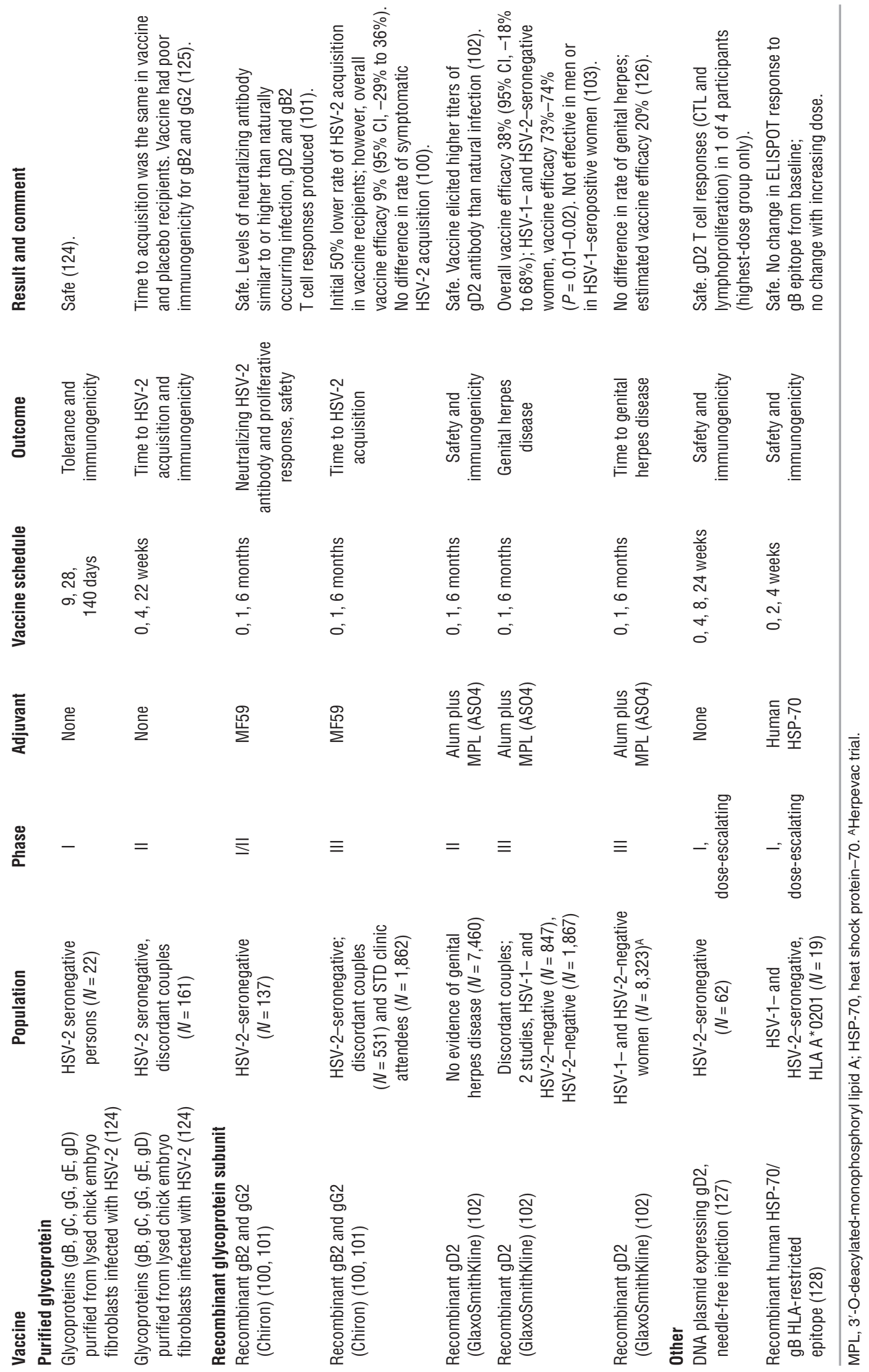


Prophylactic vaccine

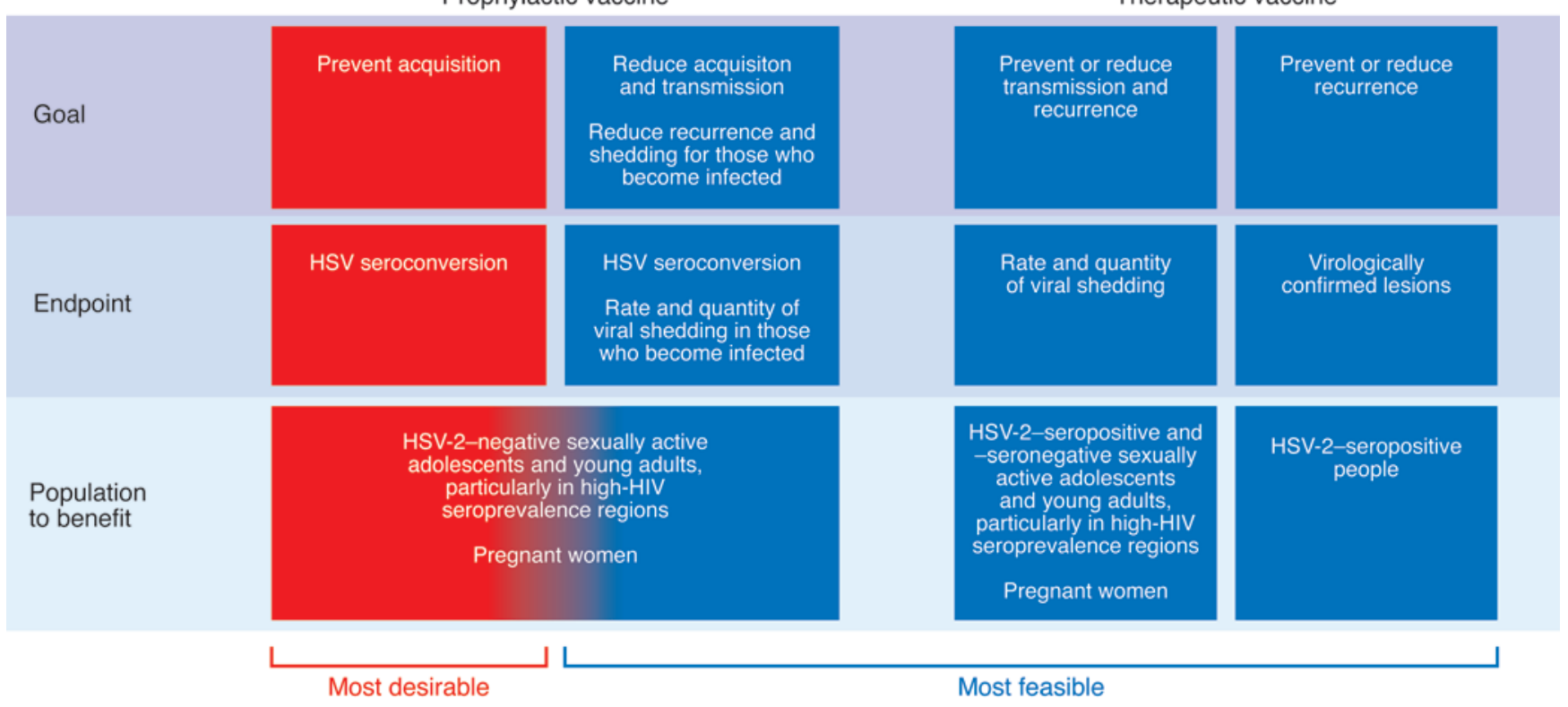

Figure 1

HSV-2 vaccine development strategies.

prior to use in human volunteers. HSV vaccine researchers should also consider virologic efficacy criteria when evaluating prophylactic and therapeutic vaccines, such as reduction or elimination of mucosal shedding or reduction of the establishment of sacral DRG latency, in addition to immunogenicity, in animal models prior to initiating human trials.

\section{Human clinical trials}

Prophylactic vaccines. Testing prophylactic HSV vaccines for efficacy requires prospective follow-up of persons at risk for HSV-2 acquisition. Even in high-risk settings, the seroconversion rate is likely to be only approximately $5 \%$ per year, making such trials a costly endeavor, similar in scope to HIV vaccine efficacy trials. Substantial efforts have been invested into glycoprotein subunits as vaccine targets, with more than 20,000 human volunteers studied in clinical trials (Table 1). A recombinant gB2 and gD2 subunit vaccine formulated with the adjuvant MF59 was safe and induced strong neutralizing antibody responses and as well as $\mathrm{CD} 4^{+} \mathrm{T}$ cell responses $(100$, 101). However, this vaccine was not successful at preventing HSV-2 infection in HSV-2-negative members of discordant heterosexual couples or STD clinic enrollees (100).

Two parallel studies showed that a recombinant gD2 subunit vaccine with an alum/monophospholipid A adjuvant (AS04) was also safe and induced both neutralizing antibody and $\mathrm{CD} 4^{+}$immune responses (102). The first trials randomized HSV-2-seronegative persons in a stable HSV-2-discordant sexual relationship, in which the source partner had clinically evident genital herpes, to receive vaccine or placebo. Although the vaccine was not efficacious in men or HSV-1-seropositive women, the vaccine reduced HSV-2 disease by $70 \%$ and HSV-2 infection by $40 \%$ in a subgroup analysis of HSV-1- and HSV-2-seronegative women (103). To further evaluate this vaccine, more than 8,000 sexually active HSV-1and HSV-2-seronegative women were enrolled in the Herpevac trial, a collaborative study sponsored by the NIH and Glaxo-
SmithKline. Preliminary results of the Herpevac trial showed no efficacy against HSV-2 disease or infection (104). These negative trials, while disappointing, have provided insights into the optimal study population, design, and endpoints for future investigations. The fact that different results were found in the two trials raises questions about whether risks of transmission and/or behavior in discordant couples in a stable relationship may be fundamentally different from those with multiple partners (104). Future trials should enroll members of both discordant monogamous couples as well as individuals with multiple partners to further evaluate this. Endpoints of interest in a prophylactic vaccine study include both acquisition of HSV-2 infection, to measure the ability of the vaccine to induce sterilizing immunity, and frequency of viral shedding. Assessment of viral shedding is more precise than identification and attribution of genital signs and symptoms, and lack of viral shedding will undoubtedly lead to lack of clinical manifestations of genital herpes. In addition, viral shedding frequency in those who are infected is also of interest to evaluate a potential effect on dynamics of transmission (Figure 1 and ref. 105).

Therapeutic vaccines. Therapeutic HSV-2 vaccines have been pursued both to improve the clinical course in individual patients and to potentially decrease HSV shedding, and hence transmission, for a public health benefit (Table 2). Most have been safe and have induced a measurable immune response. Although the first study of a recombinant gD2 vaccine adjuvanted with alum reduced the rate of virologically confirmed recurrences (106), later studies of glycoprotein vaccines failed to replicate that effect (107). Unlike the prophylactic vaccine studies, shedding data from our group indicate that the pivotal therapeutic vaccine studies can be performed efficiently with fewer than 100 individuals if viral shedding is used as an endpoint (33), whereas prophylactic vaccination studies require a much larger sample size. Viral shedding rate and quantity of virus shed could serve as useful surrogate endpoints for recurrence rate and transmission likelihood in studies of therapeutic vaccines as well. 

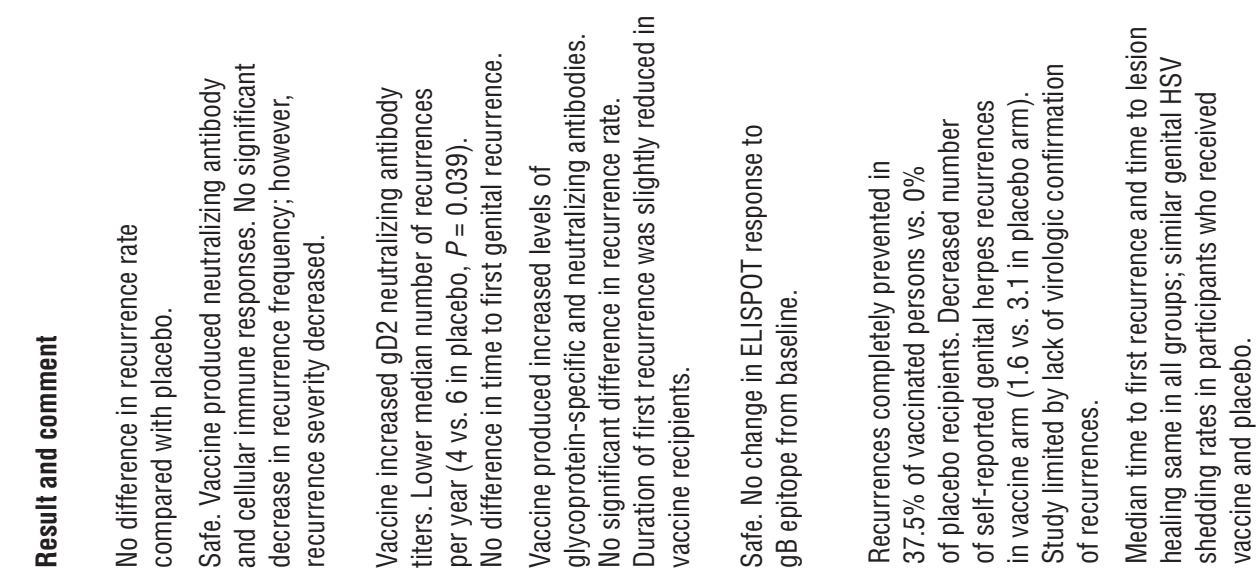

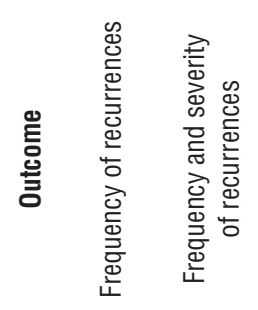
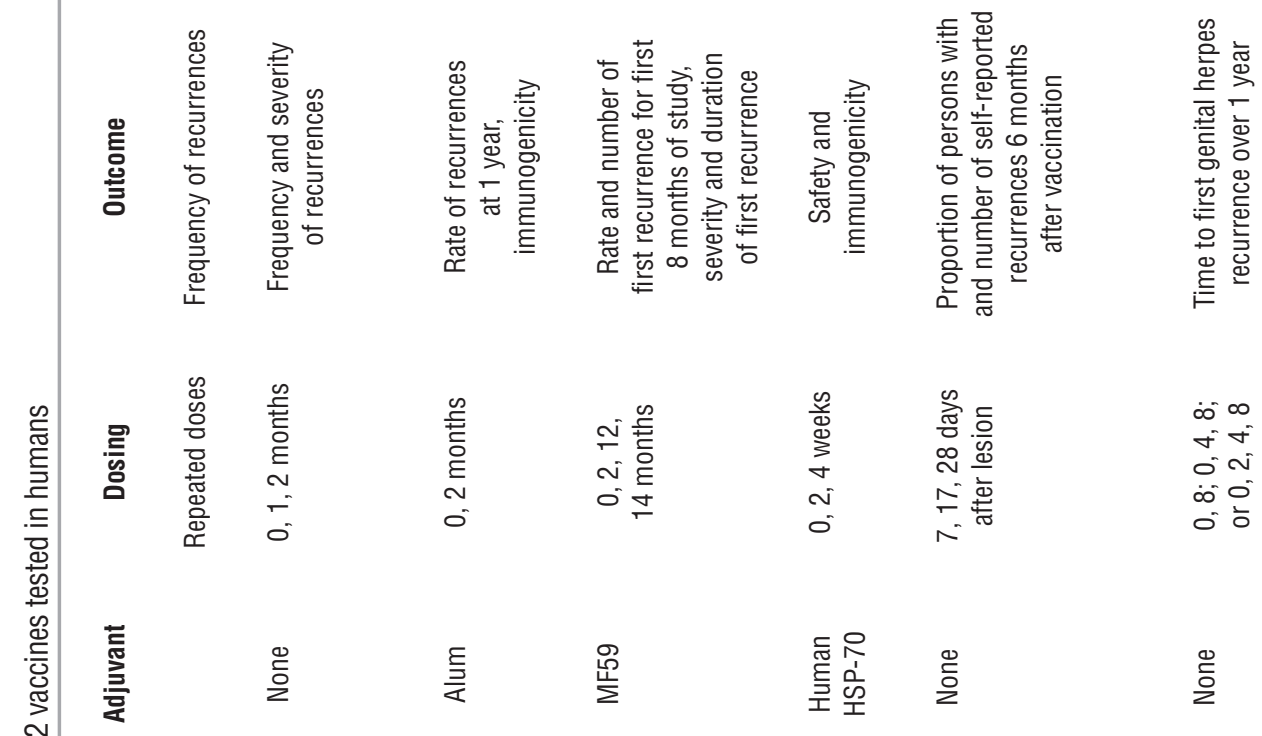

总
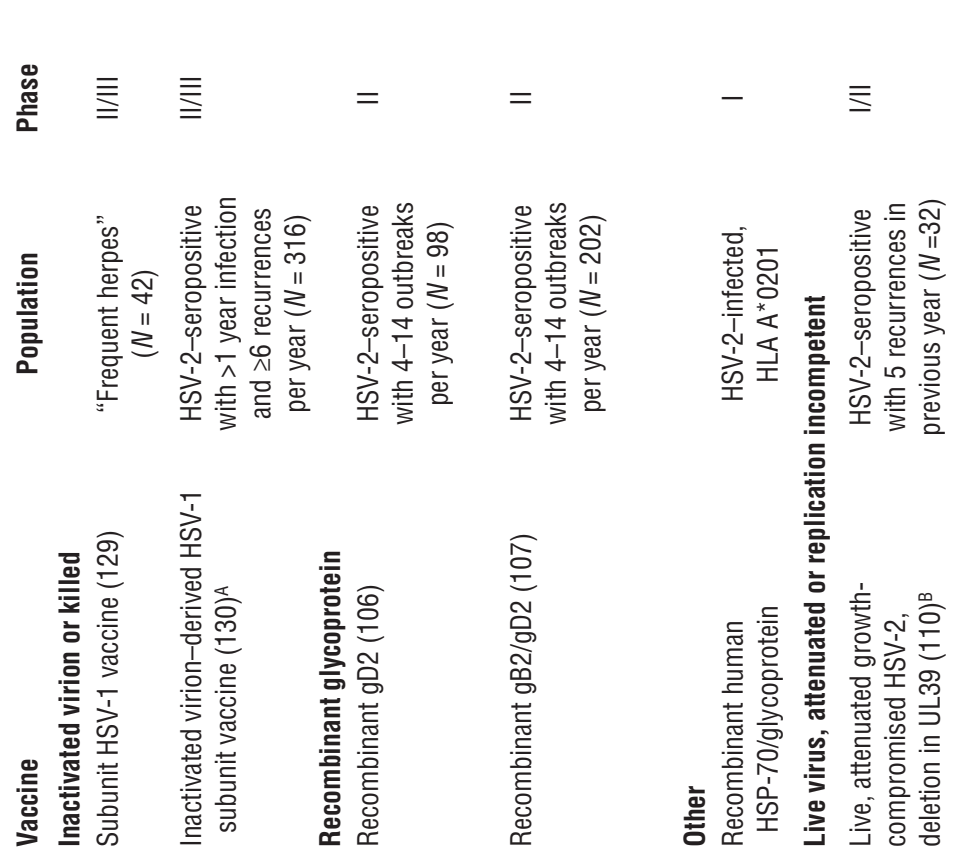

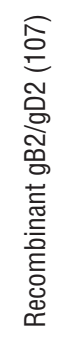
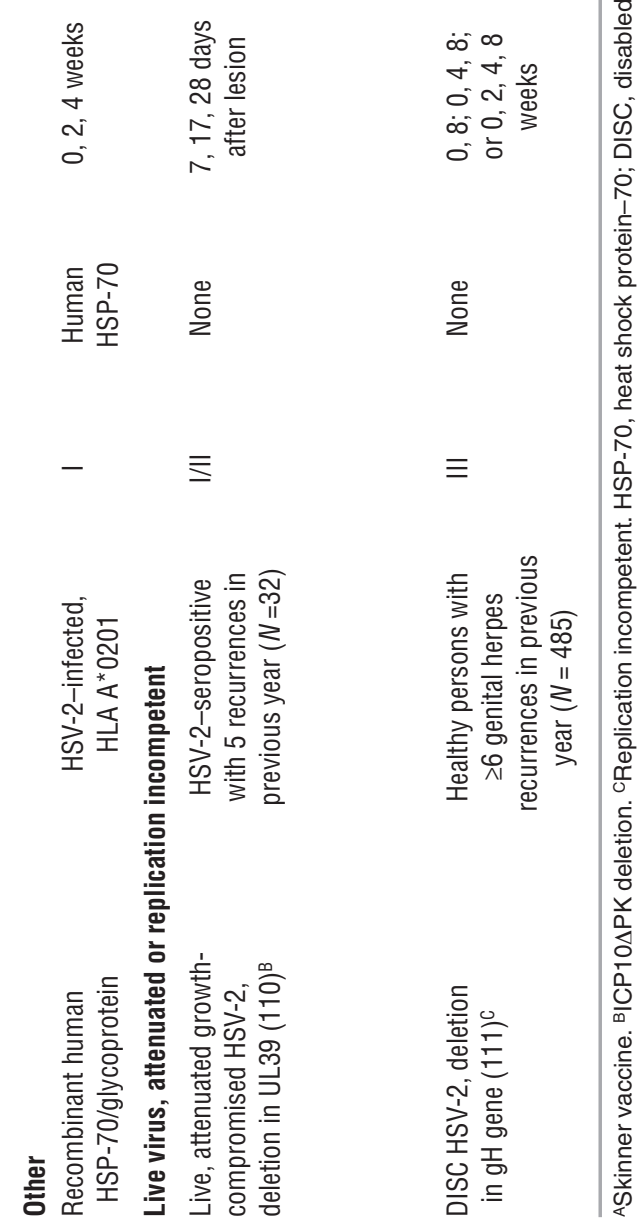
Live-virus vaccines: lessons from $V Z V$. In contrast to $H S V$, there is an effective vaccine against VZV, the other human pathogen in the alphaherpesvirus family. This live-attenuated virus vaccine prevents primary infection and VZV reactivation (zoster; ref. $108)$, making it the first example of a successful therapeutic vaccine. Whereas antibody titers to VZV do not correlate with risk of reactivation, a boosted cell-mediated immune response is associated with a decreased risk of zoster (109). These lessons should be applied to therapeutic HSV vaccine development in order to ensure that vaccine candidates induce strong cell-mediated immune responses.

Only one replication-competent HSV vaccine has been tested as a therapeutic entity in humans. This virus had a mutation in the UL39 gene and was associated with a decreased number of selfreported genital herpes recurrences compared with placebo (110); unfortunately, there was no virologic assessment of recurrences (Table 2). A disabled infectious single cycle (DISC) mutant with a $\mathrm{gH}$ deletion was tested in persons with symptomatic HSV-2, but neither shedding rates nor recurrences rates were affected (111). In this study, a limited titer of virus was used; therefore, the potential for this type of candidate vaccine has not yet been fully explored. However, several novel genetically engineered replication-incompetent vaccine candidates are in the pipeline. For example, the HSV-1 construct CJ9-gD, which is engineered to overexpress gD1 and has a dominant-negative mutation in the origin of binding protein UL9 (which inhibits viral replication), was able to protect guinea pigs from HSV-2 intravaginal challenge, with marked reduction in viral titer and lesion formation as well as amount of challenge virus establishing latency in immunized animals (112). Another pair of promising replication-incompetent vaccine constructs, dl5-29 and d15-29-41L, with deletions of essential early genes (and, in the -41 virus, the gene encoding the vhs protein), has also been effective at preventing primary infection and decreasing the titer of challenge virus establishing latency in the guinea pig model $(89,113)$. Replication-competent strains of HSV-1 with a deletion in the gE gene, which is required for neuronal spread and anterograde transport of viral components (114), or of HSV-2 with a deletion in both copies of ICP0, which has multiple virulence and immune evasion functions (115), are other innovative vaccine constructs that will require additional testing in animal models prior to moving into clinical trials.

\section{Goals of vaccination}

One of the key concerns in HSV vaccine development is whether sterilizing immunity will be feasible (116). Ideally, an HSV vaccine will be better than nature through a combination of the following mechanisms: (a) inducing sterilizing immunity in the genital tract, (b) preventing initial infection of the DRG, (c) stimulating an immune response that does not allow frequent reactivation of HSV-2 from sacral DRG, or (d) leading to high concentrations of effector cells in genital epithelia to minimize replication after virus is delivered from neurons (92). Mouse models typically require vaginal inoculation with live HSV to produce sterilizing immunity (117), and in the guinea pig model, most vaccines tested have not prevented infection of the DRG. HPV vaccines, which use virus-like particles, induce higher levels of neutralizing antibodies and memory B cells than seen in natural infection (118) and prevent genital infection with high efficacy (119), which demonstrates that vaccines that induce more potent immunity than natural infection are possible.
An alternative vaccination goal is to alter the natural history of HSV infection, by decreasing the quantity of virus establishing latency in neurons and minimizing the quantity of virus shed from genital surfaces (Figure 1). Mathematical modeling analyses have suggested that even vaccines with relatively low efficacy at preventing primary infection could have a substantial effect on the epidemic by decreasing shedding and reducing viral transmission (105). Such a vaccine would have the highest impact in high-prevalence populations (120); it is estimated that a vaccine that only marginally decreases HSV-2 susceptibility, but reduces shedding frequency among vaccinated persons who become infected by $75 \%$, could reduce HSV-2 incidence by $30 \%$ over a 10 -year period (121). Therapeutic vaccines that reduce shedding could also have a powerful effect on the HSV-2 epidemic (122).

\section{Future directions}

Over the last two decades, the field of HSV pathogenesis has progressed rapidly. There is a better understanding of the function of many HSV genes and proteins, as well as the host immune response. Importantly, we have a better appreciation for how frequently HSV reactivates from latency and is shed on mucosal surfaces, allowing for transmission to a new host. These findings point to viral shedding as an appropriate endpoint for proof-ofconcept studies. Ideally, a prophylactic vaccine would result in sterilizing immunity, which would not allow HSV to establish latency in the DRG. However, achievement of such a difficult goal will likely require additional research to understand both effective innate and acquired immunity, such that the immune response generated by the vaccine is more potent than that occurring in natural infection.

If the goal of a vaccine is to modify natural history in those already infected, or to alter the course of the infection in those with newly acquired HSV-2, we believe that vaccines should focus on changes in HSV shedding frequency and quantity in those who become infected, in parallel to HIV vaccine studies aimed at modifying the viral setpoint (123). Additional research should be devoted to establishing whether a virologic threshold for transmission exists, and toward a quantitative assessment of the prevalence of multistrain infections. Modeling studies have provided us with the ability to see how imperfect vaccines could work on a population basis; we should take advantage of such studies to have a lively debate about what type of vaccine would be attainable and effective from a personal and public health perspective. A final challenge will be having buy-in from pharmaceutical companies and regulatory bodies to pursue the potentially risky strategy of investing in a vaccine that decreases shedding rather than prevents infection. Given the reach of the HSV-2 epidemic, and the contribution of HSV-2 to HIV infection, we must be creative in our approach to this most challenging chronic viral infection.

\section{Acknowledgments}

The authors thank Joshua Schiffer for valuable comments. The authors receive funding from NIH grants K23 AI079394 (to C. Johnston), K24 AI071113 (to A. Wald), and PO1 AI30731 (to A. Wald and D.M. Koelle).

Address correspondence to: Christine Johnston, University of Washington Virology Research Clinic, Box 359928, 325 9th Ave., Seattle, Washington 98104, USA. Phone: 206.520.4340; Fax: 206.520.4371; E-mail: cjohnsto@u.washington.edu. 
1. Looker KJ, Garnett GP, Schmid GP. An estimate of the global prevalence and incidence of herpes simplex virus type 2 infection. Bull World Health Organ. 2008;86(10):805-812.

2. Center for Disease Control and Prevention. Seroprevalence of herpes simplex virus type 2 among persons aged 14-49 years--United States, 2005-2008. MMWR Morb Mortal Wkly Rep. 2010;59(15):456-459.

3. Paz-Bailey G, Ramaswamy M, Hawkes SJ, Geretti AM. Herpes simplex virus type 2: epidemiology and management options in developing countries. Sexually Transmitted Infections. 2007;83(1):16-22.

4. Xu F, et al. Trends in herpes simplex virus type 1 and type 2 seroprevalence in the United States. JAMA. 2006;296(8):964-973.

5. Mertz KJ, et al. Etiology of genital ulcers and prevalence of human immunodeficiency virus coinfection in 10 US cities. The Genital Ulcer Disease Surveillance Group. J Infect Dis. 1998;178(6):1795-1798.

6. Paz-Bailey G, et al. Changes in the etiology of sexually transmitted diseases in Botswana between 1993 and 2002: implications for the clinical management of genital ulcer disease. Clin Infect Dis. 2005;41(9):1304-1312.

7. Xu F, et al. Seroprevalence and coinfection with herpes simplex virus type 1 and type 2 in the United States, 1988-1994. J Infect Dis. 2002;185(8):1019-1024.

8. Mertz GJ, Benedetti J, Ashley R, Selke SA, Corey L. Risk factors for the sexual transmission of genital herpes. Ann Intern Med. 1992;116(3):197-202.

9. Wald A, et al. Reactivation of genital herpes simplex virus type 2 infection in asymptomatic seropositive persons. N Engl J Med. 2000;342(12):844-850.

10. Yorke JA, Hethcote HW, Nold A. Dynamics and control of the transmission of gonorrhea. Sex Transm Dis. 1978;5(2):51-56.

11. Ryder N, Jin F, McNulty AM, Grulich AE, Donovan $B$. Increasing role of herpes simplex virus type 1 in first-episode anogenital herpes in heterosexual women and younger men who have sex with men, 1992-2006. Sex Transm Infect. 2009;85(6):416-419.

12. Brown ZA, Wald A, Morrow RA, Selke S, Zeh J, Corey L. Effect of serologic status and cesarean delivery on transmission rates of herpes simplex virus from mother to infant. JAMA. 2003;289(2):203-209.

13. Looker KJ, Garnett GP. A systematic review of the epidemiology and interaction of herpes simplex virus types 1 and 2. Sex Transm Infect. 2005;81(2):103-107.

14. Balachandran N, Oba DE, Hutt-Fletcher LM. Antigenic cross-reactions among herpes simplex virus types 1 and 2, Epstein-Barr virus, and cytomegalovirus. JVirol. 1987;61(4):1125-1135.

15. Ford CA, English A, Davenport AF, Stinnett AJ. Increasing adolescent vaccination: barriers and strategies in the context of policy, legal, and financial issues. J Adolesc Health. 2009;44(6):568-574.

16. Brown ZA, et al. The acquisition of herpes simplex virus during pregnancy. $N$ Engl J Med. 1997;337(8):509-515.

17. Kimberlin DW, et al. Natural history of neonatal herpes simplex virus infections in the acyclovir era. Pediatrics. 2001;108(2):223-229.

18. Dinh T-H, Dunne EF, Markowitz LE, Weinstock H, Berman S. Assessing Neonatal Herpes Reporting in the United States, 2000-2005. Sex Transm Dis. 2008;35(1):19-21.

19. Freeman EE, Weiss HA, Glynn JR, Cross PL, Whitworth JA, Hayes RJ. Herpes simplex virus 2 infection increases HIV acquisition in men and women: systematic review and meta-analysis of longitudinal studies. AIDS. 2006;20(1):73-83.

20. Wald A, Link K. Risk of human immunodeficiency virus infection in herpes simplex virus type 2 seropositive persons: a meta-analysis. J Infect Dis. 2002;185(1):45-52.

21. Zhu J, et al. Persistence of HIV-1 receptor-positive cells after HSV-2 reactivation is a potential mecha- nism for increased HIV-1 acquisition. Nat Med. 2009;15(8):886-892.

22. Freeman EE, et al. Population-level effect of potential HSV2 prophylactic vaccines on HIV incidence in subSaharan Africa. Vaccine. 2009;27(6):940-946.

23. Workowski KA, Berman S. Sexually transmitted diseases treatment guidelines, 2010. MMWR Recomm Rep. 2010;59(RR-12):1-110.

24. Wald A, Krantz E, Selke S, Lairson E, Morrow RA, Zeh J. Knowledge of partners' genital herpes protects against herpes simplex virus type 2 acquisition. J Infect Dis. 2006;194(1):42-52.

25. Martin ET, et al. A pooled analysis of the effect of condoms in preventing HSV-2 acquisition. Arch Intern Med. 2009;169(13):1233-1240.

26 . Corey L, et al. Once-daily valacyclovir to reduce the risk of transmission of genital herpes. NEnglJ Med. 2004;350(1):11-20.

27. Celum C, et al. Effect of aciclovir on HIV-1 acquisition in herpes simplex virus 2 seropositive women and men who have sex with men: a randomised, double-blind, placebo-controlled trial. Lancet. 2008; 371(9630):2109-2119.

28. Watson-Jones D, et al. Effect of herpes simplex suppression on incidence of HIV among women in Tanzania. NEngl J Med. 2008;358(15):1560-1571.

29. Celum C, et al. Acyclovir and transmission of HIV1 from persons infected with HIV-1 and HSV-2. $N$ Engl J Med. 2010;362(5):427-439.

30. Cunningham AL, et al. The cycle of human herpes simplex virus infection: virus transport and immune control. J Infect Dis. 2006;194 suppl 1:S11-S18.

31. Mark K, et al. Rapidly cleared episodes of herpes simplex virus reactivation in immunocompetent adults. J Infect Dis. 2008;198(8):1141-1149.

32. Wald A, Corey L, Cone R, Hobson A, Davis G, Zeh $J$. Frequent genital herpes simplex virus 2 shedding in immunocompetent women. Effect of acyclovir treatment. J Clin Invest. 1997;99(5):1092-1097.

33. Tronstein E, et al. Genital shedding of herpes simplex virus among symptomatic and asymptomatic persons with HSV-2 infection. JAMA. 2011;305(14):1441-1449.

34. Wald A, Zeh J, Selke S, Ashley RL, Corey L. Virologic characteristics of subclinical and symptomatic genital herpes infections. $N$ Engl J Med. 1995;333(12):770-775

35. Crespi CM, Cumberland WG, Wald A, Corey L, Blower S. Longitudinal study of herpes simplex virus type 2 infection using viral dynamic modelling. Sex Transm Infect. 2007;83(5):359-364.

36. Schiffer JT, et al. Frequent release of low amounts of herpes simplex virus from neurons: results of a mathematical model. Sci Transl Med. 2009;1(7):7ra16.

37. Tata $S$, et al. Overlapping reactivations of herpes simplex virus type 2 in the genital and perianal mucosa. J Infect Dis. 2010;201(4):499-504.

38. Zhu J, et al. Virus-specific CD8+ T cells accumulate near sensory nerve endings in genital skin during subclinical HSV-2 reactivation. J Exp Med. 2007;204(3):595-603.

39. Johnson KE, et al. Effects of HIV-1 and herpes simplex virus type 2 infection on lymphocyte and dendritic cell density in adult foreskins from Rakai, Uganda. J Infect Dis. 2011;203(5):602-609.

40. Watson-Jones D, et al. Risk factors for herpes simplex virus type 2 and HIV among women at high risk in northwestern Tanzania: preparing for an HSV-2 intervention trial. J Acquir Immune Defic Syndr. 2007;46(5):631-642.

41. Prichard MN, et al. Evaluation of AD472, a live attenuated recombinant herpes simplex virus type 2 vaccine in guinea pigs. Vaccine. 2005; 23(46-47):5424-5431.

42. Posavad CM, et al. Detailed characterization of T cell responses to herpes simplex virus-2 in immune seronegative persons. J Immunol. 2010;184(6):3250-3259.
43. Lakeman AD, Nahmias AJ, Whitley RJ. Analysis of DNA from recurrent genital herpes simplex virus isolates by restriction endonuclease digestion. Sex Transm Dis. 1986;13(2):61-66.

44. Schmidt OW, Fife KH, Corey L. Reinfection is an uncommon occurrence in patients with symptomatic recurrent genital herpes. J Infect Dis. 1984;149(4):645-646.

45. Roest RW, et al. Genotypic analysis of sequential genital herpes simplex virus type 1 (HSV-1) isolates of patients with recurrent HSV-1 associated genital herpes. J Med Virol. 2004;73(4):601-604.

46. Roest RW, Maertzdorf J, Kant M, van der Meijden WI, Osterhaus AD, Verjans GM. High incidence of genotypic variance between sequential herpes simplex virus type 2 isolates from HIV-1-seropositive patients with recurrent genital herpes. J Infect Dis. 2006;194(8):1115-1118

47. Novak Z, et al. Cytomegalovirus Strain Diversity in Seropositive Women. J Clin Microbiol. 2008;46(3):882-886.

48. Watson-Jones D, et al. Acyclovir suppression for HIV prevention is not associated with genotypic evidence of acyclovir resistance to HSV-2: Analysis of specimens from three phase III trials [published online ahead of print August 11, 2010]. JClin Microbiol. doi:10.1128/JCM.01263-10.

49. Burrel S, Deback C, Agut H, Boutolleau D. Genotypic characterization of UL23 thymidine kinase and UL30 DNA polymerase of clinical isolates of herpes simplex virus: natural polymorphism and mutations associated with resistance to antivirals. Antimicrob Agents Chemother. 2010;54(11):4833-4842.

50. Koelle DM, Posavad CM, Barnum GR, Johnson ML, Frank JM, Corey L. Clearance of HSV-2 from recurrent genital lesions correlates with infiltration of HSV-specific cytotoxic T lymphocytes. J Clin Invest. 1998;101(7):1500-1508.

51. Siegal FP, et al. Severe acquired immunodeficiency in male homosexuals, manifested by chronic perianal ulcerative herpes simplex lesions. NEnglJMed. 1981;305(24):1439-1444.

52. Naraqi S, Jackson GG, Jonasson O, Yamashiroya HM. Prospective study of prevalence, incidence, and source of herpesvirus infections in patients with renal allografts. J Infect Dis. 1977;136(4):531-540.

53. Meyers JD, Flournoy N, Thomas ED. Infection with herpes simplex virus and cell-mediated immunity after marrow transplant. J Infect Dis. 1980;142(3):338-346.

54. Donaghy $\mathrm{H}$, et al. Role for plasmacytoid dendritic cells in the immune control of recurrent human herpes simplex virus infection. $J$ Virol. 2009;83(4):1952-1961.

55. Lund JM, Linehan MM, Iijima N, Iwasaki A. Cutting edge: Plasmacytoid dendritic cells provide innate immune protection against mucosal viral infection in situ. J Immunol. 2006;177(11):7510-7514.

56. Kurt-Jones EA, et al. Herpes simplex virus 1 interaction with Toll-like receptor 2 contributes to lethal encephalitis. Proc Natl Acad Sci U S A. 2004;101(5):1315-1320.

57. Zhang S-Y, et al. TLR3 deficiency in patients with herpes simplex encephalitis. Science. 2007; 317(5844):1522-1527.

58. Ishikawa $H, M a Z, B a r b e r ~ G N$. STING regulates intracellular DNA-mediated, type I interferon-dependent innate immunity. Nature. 2009;461(7265):788-792.

59. Casrouge A, et al. Herpes simplex virus encephalitis in human UNC-93B deficiency. Science. 2006;314(5797):308-312.

60. Casanova JL, Abel L, Quintana-Murci L. Human TLRs and IL-1Rs in host defense: natural insights from evolutionary, epidemiological, and clinical genetics. Annu Rev Immunol. 2011;29:447-491.

61. Herbst-Kralovetz MM, Pyles RB. Quantification of poly(I:C)-mediated protection against geni- 
tal herpes simplex virus type 2 infection. J Virol. 2006;80(20):9988-9997.

62. Mark KE, et al. Topical resiquimod $0.01 \%$ gel decreases herpes simplex virus type 2 genital shedding: a randomized, controlled trial. J Infect Dis. 2007;195(9):1324-1331.

63. Bochud PY, Magaret AS, Koelle DM, Aderem A Wald A. Polymorphisms in TLR2 are associated with increased viral shedding and lesional rate in patients with genital herpes simplex type 2 infection. J Infect Dis. 2007;196(4):505-509.

64. Peng $\mathrm{T}$, et al. Evasion of the mucosal innate immune system by herpes simplex virus type 2 . J Virol. 2009;83(23):12559-12568.

65. Melroe GT, DeLuca NA, Knipe DM. Herpes Simplex Virus 1 has multiple mechanisms for blocking virus-induced interferon production. J Virol. 2004 78(16):8411-8420

66. van Lint AL, et al. Herpes Simplex Virus immediateearly ICP0 protein inhibits toll-like receptor 2-dependent inflammatory responses and NF-\{kappa\}B signaling. JVirol. 2010;84(20):10802-10811.

67. Schacker T, Zeh J, Hu HL, Hill E, Corey L. Frequency of symptomatic and asymptomatic herpes simplex virus type 2 reactivations among human immunodeficiency virus-infected men. I Infect Dis. 1998;178(6):1616-1622.

68. Finke JS, Shodell M, Shah K, Siegal FP, Steinman RM. Dendritic cell numbers in the blood of HIV-1 infected patients before and after changes in antiretroviral therapy. J Clin Immunol. 2004;24(6):647-652.

69. Morrison LA. Replication-defective virus vaccineinduced protection of mice from genital herpes simplex virus 2 requires CD4 T cells. Virology. 2008;376(1):205-210

70. Iijima N, et al. Dendritic cells and B cells maximize mucosal Th1 memory response to herpes simplex virus. J Exp Med. 2008;205(13):3041-3052.

71. Simmons A, Tshcharke DC. Anti-CD8 impairs clearance of herpes simplex virus from the nervous system: implications for the fate of virally infected neurons. J Exp Med. 1992;175(5):1337-1344.

72. Knickelbein JE, Khanna KM, Yee MB, Baty CJ, Kinchington PR, Hendricks RL. Noncytotoxic lytic granule-mediated CD8+ T cell inhibition of HSV-1 reactivation from neuronal latency. Science. 2008;322(5899):268-271.

73. Verjans GMGM, et al. Selective retention of herpes simplex virus-specific $T$ cells in latently infected human trigeminal ganglia. Proc Natl Acad Sci U S A. 2007;104(9):3496-3501.

74. Schiffer JT, et al. Mucosal host immune response predicts the severity and duration of herpes simplex virus-2 genital tract shedding episodes. Proc Natl Acad Sci U S A. 2010;107(44):18973-18978.

75. Hosken N, et al. Diversity of the CD8+ T-cell response to herpes simplex virus type 2 proteins among persons with genital herpes. JVirol. 2006;80(11):5509-5515.

76. Cohen GH, et al. Localization and synthesis of an antigenic determinant of herpes simplex virus glycoprotein D that stimulates the production of neutralizing antibody. J Virol. 1984;49(1):102-108.

77. Brown ZA, et al. Neonatal herpes simplex virus infection in relation to asymptomatic maternal infection at the time of labor. $N$ Engl J Med. 1991:324(18):1247-1252.

78. Bourne N, Pyles RB, Bernstein DI, Stanberry LR. Modification of primary and recurrent genital herpes in guinea pigs by passive immunization. $J$ Gen Virol. 2002;83(pt 11):2797-2801.

79. Mester JC, Glorioso JC, Rouse BT. Protection against zosteriform spread of herpes simplex virus by monoclonal antibodies. J Infect Dis. 1991; 163(2):263-269.

80. Taylor JM, et al. Alternative entry receptors for herpes simplex virus and their roles in disease. Cell Host Microbe. 2007;2(1):19-28.

81. Heldwein EE, Lou H, Bender FC, Cohen GH,
Eisenberg RJ, Harrison SC. Crystal structure of glycoprotein B from herpes simplex virus 1 . Science. 2006;313(5784):217-220

82. Chowdary TK, Cairns TM, Atanasiu D, Cohen GH, Eisenberg RJ, Heldwein EE. Crystal structure of the conserved herpesvirus fusion regulator complex gH-gL. Nat Struct Mol Biol. 2010;17(7):882-888.

83. Carfi A, et al. Herpes simplex virus glycoprotein D bound to the human receptor HveA. Molecular Cell. 2001;8(1):169-179.

84. Perng G-C, et al. Virus-induced neuronal apoptosis blocked by the herpes simplex virus latency-associated transcript. Science. 2000;287(5457):1500-1503.

85. Jerome KR, Fox R, Chen Z, Sears AE, Lee H-y, Corey L. Herpes simplex virus inhibits apoptosis through the action of two genes, Us5 and Us3. J Virol. 1999;73(11):8950-8957.

86. Sloan DD, Jerome KR. Herpes simplex virus remodels $\mathrm{T}$-cell receptor signaling, resulting in p38-dependent selective synthesis of interleukin10. J Virol. 2007;81(22):12504-12514.

87. Fruh K, et al. A viral inhibitor of peptide transporters for antigen presentation. Nature. 1995 375(6530):415-418

88. Cotter CR, Nguyen ML, Yount JS, Lopez CB, Blaho JA, Moran TM. The virion host shut-off (vhs) protein blocks a tlr-independent pathway of herpes simplex virus type 1 recognition in human and mouse dendritic cells. PLoS One. 2010;5(2):e8684.

89. Hoshino Y, et al. Comparison of immunogenicity and protective efficacy of genital herpes vaccine candidates herpes simplex virus $2 \mathrm{dl} 5-29$ and dl529-41L in mice and guinea pigs. Vaccine. 2008; 26(32):4034-4040.

90. Thomas S, Barton S, Reay P, Marshall T, Love C, Goldsweig H, Coffin RS. Clinical development of an immune evasion gene-deleted live attenuated vaccine for HSV-2 (ImmunoVEX HSV2). 35th International Herpesvirus Workshop. Salt Lake City, Utah, USA. September 12, 2010

91. Khanna KM, Bonneau RH, Kinchington PR, Hendricks RL. Herpes simplex virus-specific memory CD8 $+\mathrm{T}$ cells are selectively activated and retained in latently infected sensory ganglia. Immunity. 2003;18(5):593-603.

92. Gebhardt T, Wakim LM, Eidsmo L, Reading PC, Heath WR, Carbone FR. Memory T cells in nonlymphoid tissue that provide enhanced local immunity during infection with herpes simplex virus. Nat Immunol. 2009;10(5):524-530.

93. Scriba M. Recurrent genital Herpes simplex virus (HSV) infection of guinea pigs. Med Microbiol Immunol. 1976;162(3-4):201-208.

94. Yim KC, et al. The cotton rat provides a novel model to study genital herpes infection and to evaluate preventive strategies. J Virol. 2005;79(23):14632-14639.

95. Lekstrom-Himes JA, Pesnicak L, Straus SE. The quantity of latent viral DNA correlates with the relative rates at which herpes simplex virus types 1 and 2 cause recurrent genital herpes outbreaks. JVirol. 1998;72(4):2760-2764.

96. Bourne N, Milligan GN, Stanberry LR, Stegall R, Pyles RB. Impact of immunization with glycoprotein D2/AS04 on herpes simplex virus type 2 shedding into the genital tract in guinea pigs that become infected. J Infect Dis. 2005;192(12):2117-2123.

97. Bernstein DI, et al. Effects of herpes simplex virus type 2 glycoprotein vaccines and CLDC adjuvant on genital herpes infection in the guinea pig. Vaccine. 2011;29(11):2071-2078.

98. Magaret A Johnston C, Wald A. Use of the designation "shedder" in mucosal detection of herpes simplex virus DNA involving repeated sampling. Sex Transm Infect. 2009;85(4):270-275.

99. Morgan C, et al. The use of nonhuman primate models in HIV vaccine development. PLoS Med. 2008;5(8):e173.

100. Corey L, et al. Recombinant glycoprotein vaccine for the prevention of genital HSV-2 infection: two randomized controlled trials. Chiron HSV Vaccine Study Group. JAMA. 1999;282(4):331-340.

101.Langenberg AG, et al. A recombinant glycoprotein vaccine for herpes simplex virus type 2: safety and immunogenicity [corrected]. Ann Intern Med. 1995;122(12):889-898.

102. Bernstein DI, et al. Safety and immunogenicity of glycoprotein $\mathrm{D}$-adjuvant genital herpes vaccine. Clin Infect Dis. 2005;40(9):1271-1281.

103. Stanberry LR, et al. Glycoprotein-D-adjuvant vaccine to prevent genital herpes. $N$ Engl J Med. 2002;347(21):1652-1661.

104. Cohen J. Painful failure of promising genital herpes vaccine. Science. 2010;330(6002):304-304.

105.Garnett GP, Dubin G, Slaoui M, Darcis T. The potential epidemiological impact of a genital herpes vaccine for women. Sex Transm Infect. 2004; 80(1):24-29.

106. Straus SE, et al. Placebo-controlled trial of vaccination with recombinant glycoprotein D of herpes simplex virus type 2 for immunotherapy of genital herpes. Lancet. 1994;343(8911):1460-1463.

107. Straus SE, et al. Immunotherapy of recurrent genital herpes with recombinant herpes simplex virus type 2 glycoproteins D and B: results of a placebo-controlled vaccine trial. J Infect Dis. 1997;176(5):1129-1134.

108. Oxman MN. Zoster vaccine: current status and future prospects. Clin Infect Dis. 2010;51(2):197-213.

109. Weinberg A, et al. Varicella-zoster virus-specific immune responses to herpes zoster in elderly participants in a trial of a clinically effective zoster vaccine. J Infect Dis. 2009;200(7):1068-1077.

110. Casanova G, et al. A double-blind study of the efficacy and safety of the ICP10deltaPK vaccine against recurrent genital HSV-2 infections. Cutis. 2002;70(4):235-239

111. de Bruyn $\mathrm{G}$, et al. A randomized controlled trial of a replication defective ( $\mathrm{gH}$ deletion) herpes simplex virus vaccine for the treatment of recurrent genital herpes among immunocompetent subjects. Vaccine. 2006;24(7):914-920.

112.Brans R, Yao F. Immunization with a dominantnegative recombinant Herpes Simplex Virus (HSV) type 1 protects against HSV-2 genital disease in guinea pigs. BMC Microbiol. 2010;10:163.

113. Hoshino Y, et al. Protection from Herpes Simplex Virus (HSV)-2 infection with replication-defective HSV-2 or glycoprotein D2 vaccines in HSV-1seropositive and HSV-1-seronegative guinea pigs. J Infect Dis. 2009;200(7):1088-1095.

114. Brittle EE, Wang F, Lubinski JM, Bunte RM, Friedman HM. A replication-competent, neuronal spreaddefective, live attenuated herpes simplex virus type 1 vaccine. J Virol. 2008;82(17):8431-8441.

115. Halford WP, Puschel R, Gershburg E, Wilber A, Gershburg S, Rakowski B. A live-attenuated HSV-2 ICP0- virus elicits 10 to 100 times greater protection against genital herpes than a glycoprotein $\mathrm{D}$ subunit vaccine. PLoS ONE. 2011;6(3):e17748.

116. Koelle DM, Corey L. Recent progress in herpes simplex virus immunobiology and vaccine research. Clin Microbiol Rev. 2003;16(1):96-113.

117. Parr EL, Parr MB. Immunoglobulin G, plasma cells, and lymphocytes in the murine vagina after vaginal or parenteral immunization with attenuated herpes simplex virus type 2. J Virol. 1998;72(6):5137-5145.

118. Schwarz TF, Leo O. Immune response to human papillomavirus after prophylactic vaccination with AS04adjuvanted HPV-16/18 vaccine: Improving upon nature. Gynecol Oncol. 2008;110(3 suppl 1):S1-S10.

119.Garland SM, et al. Quadrivalent vaccine against human papillomavirus to prevent anogenital diseases. NEngJ Med. 2007;356(19)1928-1943.

120.Schwartz EJ, Blower S. Predicting the potential individual- and population-level effects of imperfect herpes simplex virus type 2 vaccines. J Infect Dis. 
2005;191(10):1734-1746.

121. Alsallaq RA, Schiffer JT, Longini IM Jr, Wald A, Corey L, Abu-Raddad LJ. Population level impact of an imperfect prophylactic vaccine for herpes simplex virus-2. Sex Transm Dis. 2010;37(5):290-297.

122. Schwartz EJ, Bodine EN, Blower S. Effectiveness and efficiency of imperfect therapeutic HSV-2 vaccines. Hum Vaccin. 2007;3(6):231-238.

123. Barouch DH, et al. Control of viremia and prevention of clinical AIDS in rhesus monkeys by cytokine-augmented DNA vaccination. Science. 2000;290(5491):486-492.

124. Mertz GJ, et al. Herpes simplex virus type-2 glycoprotein-subunit vaccine: tolerance and humoral and cellular responses in humans. J Infect Dis. 1984;150(2):242-249.

125. Mertz GJ, et al. Double-blind, placebo-controlled trial of a herpes simplex virus type 2 glycoprotein vaccine in persons at high risk for genital herpes infection. J Infect Dis. 1990;161(4):653-660.

126.NIAID/NIH. Study finds genital herpes vaccine ineffective in women. NIAID web site. http://www. niaid.nih.gov/news/newsreleases/2010/Pages/ Herpevac.aspx. Accessed October 14, 2011.

127. Cattamanchi A, et al. Phase I study of a herpes simplex virus type 2 (HSV-2) DNA vaccine administered to healthy, HSV-2-seronegative adults by a needle-free injection system. Clin Vaccine Immunol. 2008;15(11):1638-1643.

128. Koelle DM, et al. Phase I dose-escalation study of a monovalent heat shock protein 70 -herpes simplex virus type 2 (HSV-2) peptide-based vaccine designed to prime or boost CD8 T-cell responses in HSV-naïve and HSV-2-infected subjects. Clin Vaccine Immunol. 2008;15(5):773-782.

129. Kutinova L, et al. Placebo-controlled study with subunit herpes simplex virus vaccine in subjects suffering from frequent herpetic recurrences. Vaccine. 1988;6(3):223-228.

130.Skinner GR, et al. The efficacy and safety of Skinner herpes simplex vaccine towards modulation of herpes genitalis; report of a prospective double-blind placebo-controlled trial. Med Microbiol Immunol. 1997;186(1):31-36.

131. Meignier B, Longnecker R, Roizman B. In vivo behavior of genetically engineered herpes simplex viruses R7017 and R7020: construction and evaluation in rodents. J Infect Dis. 1988;158(3):602-614.

132. Spector FC, et al. Evaluation of a live attenuated recombinant virus RAV 9395 as a herpes simplex virus type 2 vaccine in guinea pigs. J Infect Dis. 1998;177(5):1143-1154.

133. Wachsman M, Kulka M, Smith CC, Aurelian L. A growth and latency compromised herpes simplex virus type 2 mutant (ICP10[Delta]PK) has prophylactic and therapeutic protective activity in guinea pigs. Vaccine. 2001;19(15-16):1879-1890.

134. McLean CS, Ni Challanain D, Duncan I, Boursnell $\mathrm{ME}$, Jennings R, Inglis SC. Induction of a protective immune response by mucosal vaccination with a DISC HSV-1 vaccine. Vaccine. 1996;14(10):987-992.

135. Boursnell ME, et al. A genetically inactivated herpes simplex virus type 2 (HSV-2) vaccine provides effective protection against primary and recurrent HSV-2 disease. J Infect Dis. 1997;175(1):16-25.

136. Da Costa XJ, Bourne N, Stanberry LR, Knipe DM. Construction and characterization of a replicationdefective herpes simplex virus 2 ICP8 mutant strain and its use in immunization studies in a guinea pig model of genital disease. Virology. 1997;232(1):1-12.

137. Hoshino Y, et al. Comparative efficacy and immunogenicity of replication-defective, recombinant glycoprotein, and DNA vaccines for herpes simplex virus 2 infections in mice and guinea pigs. J Virol. 2005;79(1):410-418.

138. Heineman TC, Connelly BL, Bourne N, Stanberry LR, Cohen J. Immunization with recombinant varicellazoster virus expressing herpes simplex virus type 2 glycoprotein D reduces the severity of genital herpes in guinea pigs. JVirol. 1995;69(12):8109-8113.

139. Bernstein DI. Effect of route of vaccination with vaccinia virus expressing HSV-2 glycoprotein D on protection from genital HSV-2 infection. Vaccine. 2000;18(14):1351-1358.

140.Natuk RJ, et al. Recombinant vesicular stomatitis virus vectors expressing herpes simplex virus type 2 $\mathrm{gD}$ elicit robust CD4+ Th1 immune responses and are protective in mouse and guinea pig models of vaginal challenge. J Virol. 2006;80(9):4447-4457.

141. Bourne N, Stanberry LR, Bernstein DI, Lew D.
DNA immunization against experimental genital herpes simplex virus infection. J Infect Dis. 1996;173(4):800-807.

142.McClements WL, Armstrong ME, Keys RD, Liu MA. The prophylactic effect of immunization with DNA encoding herpes simplex virus glycoproteins on HSV-induced disease in guinea pigs. Vaccine. 1997;15(8):857-860.

143. Mester JC, Twomey TA, Tepe ET, Bernstein DI. Immunity induced by DNA immunization with herpes simplex virus type 2 glycoproteins B and C. Vaccine. 1999;18(9-10):875-883.

144.Fotouhi F, Soleimanjahi H, Roostaee MH, Behzadian F. Enhancement of protective humoral immune responses against Herpes simplex virus-2 in DNAimmunized guinea-pigs using protein boosting. FEMS Immunol Med Microbiol. 2008;54(1):18-26.

145. Morello CS, Levinson MS, Kraynyak KA, Spector DH. Immunization with herpes simplex virus 2 (HSV-2) genes plus inactivated HSV-2 is highly protective against acute and recurrent HSV-2 disease. J Virol. 2011;85(7):3461-3472.

146.O'Hagan D, Goldbeck C, Ugozzoli M, Ott G, Burke RL. Intranasal immunization with recombinant gD2 reduces disease severity and mortality following genital challenge with herpes simplex virus type 2 in guinea pigs. Vaccine. 1999;17(18):2229-2236.

147. Simms JR, Heath AW, Jennings R. Use of herpes simplex virus (HSV) type 1 ISCOMS 703 vaccine for prophylactic and therapeutic treatment of primary and recurrent HSV-2 infection in guinea pigs. J Infect Dis. 2000;181(4):1240-1248.

148. Bourne N, et al. Herpes simplex virus (HSV) type 2 glycoprotein D subunit vaccines and protection against genital HSV-1 or HSV-2 disease in guinea pigs. J Infect Dis. 2003;187(4):542-549.

149. Quenelle DC, Collins DJ, Marciani DJ, Kern ER. Effect of immunization with herpes simplex virus type-1 (HSV-1) glycoprotein D (gD) plus the immune enhancer GPI-0100 on infection with HSV-1 or HSV-2. Vaccine. 2006;24(10):1515-1522.

150.Bernstein DI, et al. The adjuvant CLDC increases protection of a herpes simplex type 2 glycoprotein $\mathrm{D}$ vaccine in guinea pigs. Vaccine. 2010; 28(21):3748-3753. 